\title{
SELEKSI PROPOSAL PENELITIAN DAN PENGABDIAN MASYARAKAT DOSEN POLITEKNIK NEGERI SAMARINDA MENGGUNAKAN METODE TOPSIS
}

\author{
Karyo Budi Utomo', Agnes S. Niken Pembayun ${ }^{2}$, \\ Program Studi Teknik Informatika \\ Politeknik Negeri Samarinda \\ e-Mail: karyobudi@gmail.com ${ }^{1)}$, agnesnikk@ gmail.com $^{2)}$
}

\begin{abstract}
Abstrak - Perguruan tinggi berperan sangat penting salah satunya melalui penerapan Tri Dharma Perguruan Tinggi yaitu pendidikan , penelitian dan pengabdian kepada masyarakat. Dosen juga berkewajiban dalam melaksanakan Tri Dharma Perguruan Tinggi salah satunya adalah penelitian. Kesempatan peningkatan kualitas yang dilakukan secara kompetitif tentunya memerlukan proses seleksi secara selektif, untuk mendapatkan peneliti yang berkualitas. Kegiatan ini biasanya diikuti oleh banyak dosen, dengan jumlah kriteria yang berbeda. Hal tersebut sangat memakan banyak waktu. Oleh karena itu perlu adanya sebuah pendukung keputusan dalam proses penyeleksian tersebut. Untuk melakukan perhitungan dan perengkingan peneliti menggunakan metode Technique for Order Preference by Similarity to Ideal Solution (TOPSIS). Metode ini dipilih karena perhitungannya yang tidak rumit, serta memiliki kemampuan untuk menentukan keputusan dalam bentuk matematis yang sederhana.
\end{abstract}

Kata Kunci: seleksi, Technique for Order Preference by Similarity to Ideal Solution (TOPSIS).

\section{PENDAHULUAN}

Seleksi adalah proses pemilihan orang-orang yang memenuhi kriteria untuk menepati posisi yang tersedia berdasarakan kondisi yang ada pada perusahaan [1]. Dalam melakukan seleksi harus dilakukan sesuai dengan peraturan dan ketetapan yang sudah berlaku.

Technique for Order Preference by Similarity to Ideal Solution (TOPSIS) merupakan metode dimana alternatif terpilih memiliki jarak terpendek dari solusi ideal positif dan jarak terpanjang dari solusi ideal negatif. Metode ini diperkenalkan pertamakali oleh Yoon dan Hwang [2].

Penelitian merupakan salah satu kegiatan dalam perguruan tinggi untuk peningkatan mutu Pendidikan. Program penelitian yang diselenggarakan oleh Direktorat Jendral Penguatan Riset dan Pengembangan untuk peneliti diperguruan tinggi meliputi beberapa skema. Banyaknya skema ini memakan waktu dalam proses penyeleksian.

Berdasarkan uraian tersebut, maka penelitian ini membahas tentang seleksi yang akan diterapkan pada proposal penelitian dengan metode TOPSIS yang disesuaikan dengan ketetapan yang telah berlaku.

\section{METODOLOGI DAN BAHAN PENELITIAN}

Metodologi dalam penelitian ini memiliki beberapa langkah. Adapun tahapan yang dilakukan adalah :

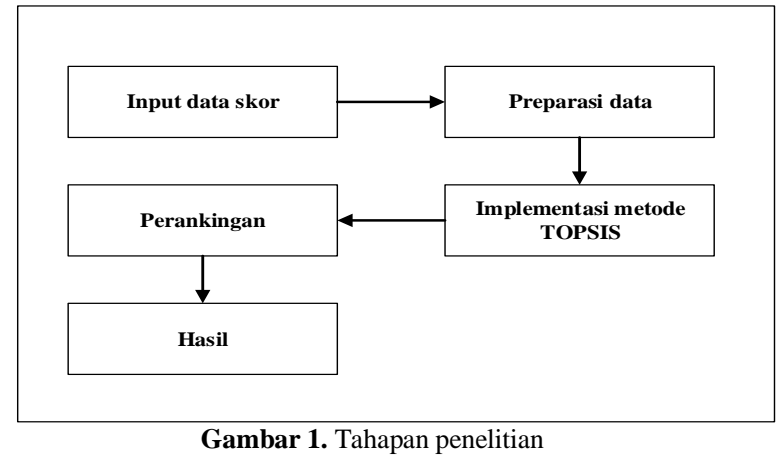

1. Memberikan skor terhadap setiap alternatif sesuai kriteria (setiap alternatif memiliki dua skor) .

2. Pada tahap preparasi data dilakukan 2 tahapan yaitu tahap penjumlahan dan merubah dimensi matriks.

3. Melakukan proses perhitungan dengan metode TOPSIS sesuai dengan bobot setiap kriteria.

4. Melakukan proses perengkingan berdasarkan perhitungan nilai dari masingmasing alternatif.

5. Hasil yang didapat adalah urutan perengkingan.

\subsection{Kriteria}

Dalam penelitian ini menggunakan kriteria yang didapat dalam Buku Panduan Pelaksanaan Penelitian dan Pengabdian Kepada Masyarakat Edisi XI. Kriteria yang di ambil sesuai dengan skema penelitian dosen pemula. Pada tahap ini peneliti menentukan kriteria diberi kode $\mathrm{C} 1$ sampai C5 sebagai berikut: 
Tabel 1. Kriteria

\begin{tabular}{l|l}
\hline Kode & Kriteria \\
\hline C1 & Perumusan masalah \\
\hline C2 & $\begin{array}{l}\text { Peluang luaran } \\
\text { penelitian }\end{array}$ \\
\hline C3 & Metode penelitian \\
\hline C4 & Tinjauan pustaka \\
\hline C5 & Kelayakan penelitian \\
\hline
\end{tabular}

\subsection{Alternatif}

Data alternatif yang digunakan dalam penelitian ini diambil dari Pusat Penelitian dan Pengabdian Masyarakat (P3M) di Politeknik Negeri Samarinda. Data alternatif yang digunakan merupakan data pada tahun 2015.

Table 2. Data Alternatif

\begin{tabular}{l|l}
\hline Kode & Nama Ketua Penelitian \\
\hline A1 & Sirajuddin, S.T., M.Si \\
\hline A2 & Mustafa, S.T., M.Si \\
\hline A3 & Mardhiyah Nadir, S.T., M.T \\
\hline A4 & Syarifuddin Oko, S.Si., M.Sc \\
\hline A5 & Dr. Darius Shyafary, M.Si \\
\hline A6 & Cisyulia Octavia HS, S.T., M.T \\
\hline A7 & Farandika Metandi, BCompSc.,MM.,M.Cs \\
\hline A8 & Abdul Najib, S.Kom.,M.Cs \\
\hline A9 & Karyo Budi Utomo, S.Kom.,M.Eng \\
\hline A10 & Ahmad Rofiq Hakim, S.Pd.,M.Kom \\
\hline A11 & Agusma Wajiansyah, SST.,MT \\
\hline A12 & Supriadi, SST.,MT \\
\hline A13 & Anton Topadang, S.Kom., M.Sc \\
\hline A14 & Tien Rahayu Tulili, S.T., M.Tech \\
\hline
\end{tabular}

\subsection{Proses TOPSIS}

Secara umum prosedur TOPSIS mengikuti langkah-langkah sebagai berikut[3]:

a. Membuat matriks keputusan yang ternormalisasi.

b. Membuat matriks keputusan ternormalisasi terbobot.

c. Menentukan matriks solusi ideal positif dan matriks solusi ideal negatif

d. Menentukan jarak antara nilai setiap alternatif dengan matriks solusi ideal positif dan matriks solusi ideal negatif.

e. Menentukan nilai preferensi untuk setiap alternatif.

Garis besar proses perhitungan metode TOPSIS ditunjukan pada gambar berikut.
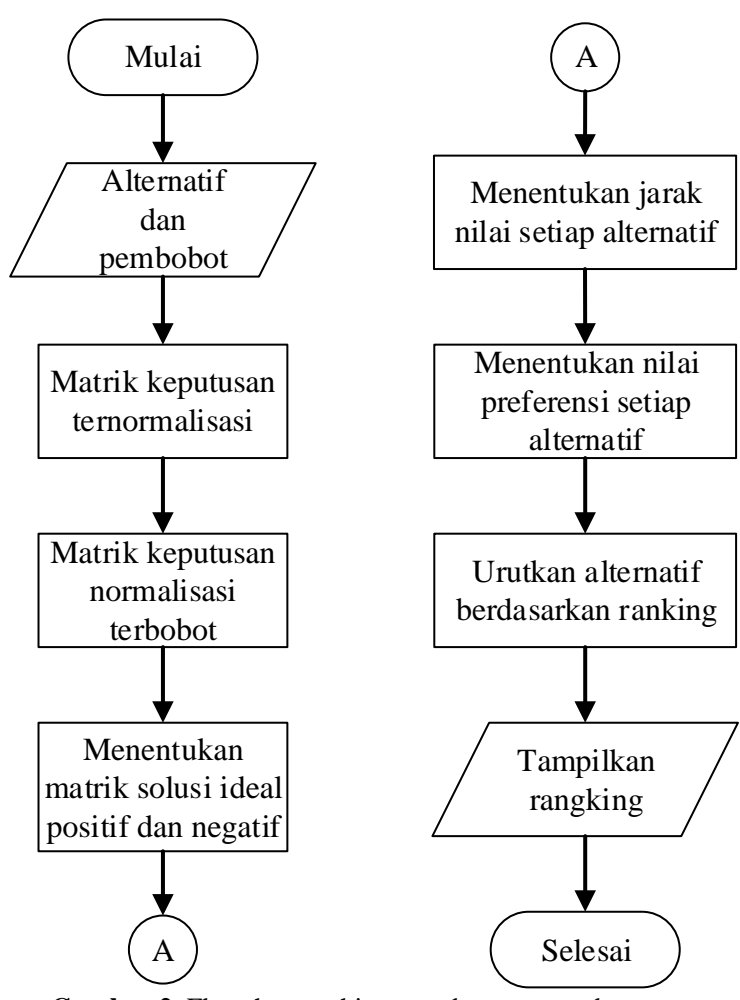

Gambar 2. Flowchart perhitungan dengan metode TOPSIS

Berdasarkan pada gambar 2 proses pertama setelah input alternatif dan pembobot adalah membuat matriks keputusan yang ternormalisasi. Digunakan persamaan sebagai berikut

$$
r_{i j}=\frac{x_{i j}}{E_{i}}=\frac{x_{i j}}{\sqrt{\sum_{i=1}^{m} x_{i j}^{2}}}
$$

Keterangan:

$r_{i j}$ adalah elemen dari matrikss keputusan yang ternormalisasi R,

$x_{i j}$ adalah elemen dari matriks keputusan X.

Selanjutnya pembobotan pada matriks yang telah dinormalisasi menggunakan persamaan (2)

$$
v_{i j}=w_{j} \cdot r_{i j}
$$

Kemudian menentukan solusi ideal positif $\left(\mathrm{A}^{+}\right)$dan solusi ideal positif $\left(\mathrm{A}^{-}\right)$berdasarkan persamaan (3) dan (4) sebagai berikut :

$A^{+}=\left(y_{1}^{+}, y_{2}^{+}, \ldots, y_{n}^{+}\right)$;

$A^{-}=\left(y_{1}^{-}, y_{2}^{-}, \ldots, y_{n}^{-}\right)$;

Dengan

$\mathrm{y}_{\mathrm{j}}^{+}=\left\{\begin{array}{l}\frac{\max }{\mathrm{i}} \mathrm{y}_{\mathrm{ij}} ; \text { jika } \mathrm{j} \text { adalah atribut keuntungan } \\ \frac{\min }{\mathrm{i}} \mathrm{y}_{\mathrm{ij}} ; \quad \text { jika } \mathrm{j} \text { adalah atribut biaya }\end{array}\right.$ (5)

$\mathrm{y}_{\mathrm{j}}^{-}= \begin{cases}\frac{\min }{\mathrm{i}} \mathrm{y}_{\mathrm{ij}} ; & \text { jika } \mathrm{j} \text { adalah atribut keuntungan } \\ \frac{\mathrm{max}}{\mathrm{i}} \mathrm{y}_{\mathrm{ij}} ; & \text { jika } \mathrm{j} \text { adalah atribut biaya }\end{cases}$ ...(6)

Keterangan:

$v_{i j}$ adalah elemen dari matriks normalisasi terbobot 
$v_{j}^{+}(\mathrm{j}=1,2,3, \ldots, \mathrm{n})$ adalah elemen matriks solusi ideal positif,

$v_{j}^{-}=(\mathrm{j}=1,2,3, \ldots, \mathrm{n})$ adalah elemen matriks solusi ideal negatif.

Selanjutnya menghitung separasi atau jarak alternatif dari solusi ideal positif dan negatif. Jarak antara alternatif $A_{i}$ dengan solusi ideal positif dapat dihitung menggunakan persamaan (7) dan jarak antara alternatif $A_{i}$ dengan solusi ideal negatif dapat dihitung menggunakan persamaan (8).

$$
\begin{aligned}
s_{i}^{+} & =\sqrt{\sum_{j=1}^{n}\left(v_{j}^{+}-v_{i j}\right)^{2}} \\
s_{i}^{-} & =\sqrt{\sum_{j=1}^{n}\left(v_{i j}-v_{j}^{-}\right)^{2}} .
\end{aligned}
$$

Keterangan :

$s_{i}^{+}$adalah jarak alternatif ke-I dari solusi ideal positif

$s_{i}^{-}$adalah jarak alternatif ke-I dari solusi ideal negatif

$v_{i j}$ adalah elemen dari matriks normalisasi terbobot

$v_{j}^{+}$adalah elemen matriks solusi ideal positif

$v_{j}^{-}$adalah elemen matriks solusi ideal negatif

Kemudian menentukan kedekatan relatif terhadap solusi ideal positif. Kedekatan relatif dari $\mathrm{A}^{+}$dengan solusi ideal $\mathrm{A}^{-}$dapat dihitung dengan persamaan (9)

$$
C_{i}=\frac{s_{i}^{-}}{s_{i}^{-}+s_{i}^{+}}
$$

Keterangan :

$C_{i}$ adalah kedekatan relatif untuk setiap alternatif $S_{i}^{+}$adalah jarak alternatif ke-I dari solusi ideal positif

$s_{i}^{-}$ntukan kedekatan relatif terhadap solusi ideal negatif

Selanjutnya alternatif diurutkan sesuai nilai $C_{i}$ dari yang tertinggi ke terendah yang menunjukan bahwa alternatif tersebut lebih dipilih

\section{HASIL DAN PEMBAHASAN}

\section{a. Data Penelitian}

Pada penelitian ini bobot yang digunakan berasal dari Buku Panduan Pelaksanaan Penelitian dan Pengabdian Kepada Masyarakat Edisi XI. Proses seleksi dilakukan secara selektif dan objektif sesuai bobot penilaian dari masing-masing kriteria. Nilai bobot kepentingan dari masing-masing kriteria dapat dilihat dari tabel 3:

Tabel 3. Bobot kepentingan

\begin{tabular}{l|l}
\hline Kriteria & \multicolumn{1}{l}{ Bobot kepentingan } \\
\hline C1 & $25 \%$ \\
\hline C2 & $25 \%$ \\
\hline C3 & $25 \%$ \\
\hline
\end{tabular}

\begin{tabular}{|l|l|}
\hline $\mathrm{C} 4$ & $15 \%$ \\
\hline $\mathrm{C} 5$ & $10 \%$ \\
\hline
\end{tabular}

Data yang didapat dari P3M POLNES dimodelkan terlebih dahulu sesuai dengan permodelan nilai yang telah di buat sebelumnya. Data matriks keputusan dapat dilihat pada tabel 4 .

Tabel 4. Matriks Keputusan

\begin{tabular}{c|c|c|c|c|c}
\hline & C1 & C2 & C3 & C4 & C5 \\
\hline A1 & 5 & 10 & 9 & 7 & 13 \\
\hline A2 & 7 & 9 & 10 & 7 & 13 \\
\hline A3 & 11 & 10 & 12 & 12 & 7 \\
\hline A4 & 8 & 10 & 12 & 11 & 8 \\
\hline A5 & 11 & 10 & 10 & 13 & 12 \\
\hline A6 & 7 & 9 & 13 & 13 & 8 \\
\hline A7 & 10 & 10 & 6 & 13 & 9 \\
\hline A8 & 6 & 10 & 11 & 7 & 9 \\
\hline A9 & 11 & 10 & 10 & 11 & 13 \\
\hline A10 & 7 & 10 & 7 & 9 & 12 \\
\hline A11 & 9 & 11 & 12 & 13 & 12 \\
\hline A12 & 8 & 8 & 13 & 9 & 10 \\
\hline A13 & 12 & 8 & 7 & 11 & 13 \\
\hline A14 & 11 & 10 & 7 & 10 & 12 \\
\hline
\end{tabular}

\section{b. Proses Perhitungan}

Setelah menentuka matriks keputusan, langkah selanjutnya adalah melakukan normalisasi pada matriks tersebut dengan menggunakan persamaan (1). Hasil perhitungan normalisasi matriks keputusan dapat dilihat pada tabel 5:

Tabel 5. Normalisasi Normalisas

\begin{tabular}{c|c|c|c|c|c} 
& C1 & C2 & C3 & C4 & C5 \\
\hline A1 & 0.0745 & 0.1477 & 0.1350 & 0.1038 & 0.1647 \\
\hline A2 & 0.1044 & 0.1329 & 0.1500 & 0.1038 & 0.1647 \\
\hline A3 & 0.1640 & 0.1477 & 0.1800 & 0.1780 & 0.0886 \\
\hline A4 & 0.1193 & 0.1477 & 0.1800 & 0.1632 & 0.1013 \\
\hline A5 & 0.1640 & 0.1477 & 0.1500 & 0.1928 & 0.1520 \\
\hline A6 & 0.1044 & 0.1329 & 0.1950 & 0.1928 & 0.1013 \\
\hline A7 & 0.1491 & 0.1477 & 0.0900 & 0.1928 & 0.1140 \\
\hline A8 & 0.0894 & 0.1477 & 0.1650 & 0.1038 & 0.1140 \\
\hline A9 & 0.1640 & 0.1477 & 0.1500 & 0.1632 & 0.1647 \\
\hline A10 & 0.1044 & 0.1477 & 0.1050 & 0.1335 & 0.1520 \\
\hline A11 & 0.1342 & 0.1624 & 0.1800 & 0.1928 & 0.1520 \\
\hline A12 & 0.1193 & 0.1181 & 0.1950 & 0.1335 & 0.1266 \\
\hline A13 & 0.1789 & 0.1181 & 0.1050 & 0.1632 & 0.1647 \\
\hline A14 & 0.1640 & 0.1477 & 0.1050 & 0.1483 & 0.1520 \\
\hline
\end{tabular}

Langkah berikutnya adalah melakukan pembobotan pada matriks keputusan ternormalisasi. Untuk mencari nilai pembobotan 
pada matriks keputusan ternormalisai digunakan persamaan (2). Bobot yang digunakan dapat dilihat pada tabel 3. Hasil pembobotan matriks keputusan ternormalisasi dapat dilihat pada tabel 6 .

Tabel 6. Matriks normalisasi terbobot

\begin{tabular}{|c|c|c|c|c|c|}
\hline \multicolumn{6}{|c|}{ Normalisasi Terbobot } \\
\hline & $\mathrm{C} 1$ & $\mathrm{C} 2$ & C3 & $\mathrm{C} 4$ & C5 \\
\hline $\mathrm{A} 1$ & $\begin{array}{c}1.864 \\
4\end{array}$ & $\begin{array}{c}3.692 \\
8\end{array}$ & $\begin{array}{c}3.375 \\
5\end{array}$ & $\begin{array}{c}1.557 \\
9\end{array}$ & $\begin{array}{c}1.647 \\
0\end{array}$ \\
\hline $\mathrm{A} 2$ & $\begin{array}{c}2.610 \\
1\end{array}$ & $\begin{array}{c}3.323 \\
5\end{array}$ & $\begin{array}{c}3.750 \\
6\end{array}$ & $\begin{array}{c}1.557 \\
9\end{array}$ & $\begin{array}{c}1.647 \\
0\end{array}$ \\
\hline A3 & $\begin{array}{c}4.101 \\
7\end{array}$ & $\begin{array}{c}3.692 \\
8\end{array}$ & $\begin{array}{c}4.500 \\
7\end{array}$ & $\begin{array}{c}2.670 \\
8\end{array}$ & $\begin{array}{c}0.886 \\
8\end{array}$ \\
\hline A4 & $\begin{array}{c}2.983 \\
0\end{array}$ & $\begin{array}{c}3.692 \\
8\end{array}$ & $\begin{array}{c}4.500 \\
7\end{array}$ & $\begin{array}{c}2.448 \\
2\end{array}$ & $\begin{array}{c}1.013 \\
5\end{array}$ \\
\hline A5 & $\begin{array}{c}4.101 \\
7\end{array}$ & $\begin{array}{c}3.692 \\
8 \\
\end{array}$ & $\begin{array}{c}3.750 \\
6\end{array}$ & $\begin{array}{c}2.893 \\
4 \\
\end{array}$ & $\begin{array}{c}1.520 \\
3 \\
\end{array}$ \\
\hline A6 & $\begin{array}{c}2.610 \\
1\end{array}$ & $\begin{array}{c}3.323 \\
5 \\
\end{array}$ & $\begin{array}{c}4.875 \\
7\end{array}$ & $\begin{array}{c}2.893 \\
4\end{array}$ & $\begin{array}{c}1.013 \\
5\end{array}$ \\
\hline A7 & $\begin{array}{c}3.728 \\
8\end{array}$ & $\begin{array}{c}3.692 \\
8\end{array}$ & $\begin{array}{c}2.250 \\
3\end{array}$ & $\begin{array}{c}2.893 \\
4\end{array}$ & $\begin{array}{c}1.140 \\
2\end{array}$ \\
\hline A8 & $\begin{array}{c}2.237 \\
3\end{array}$ & $\begin{array}{c}3.692 \\
8\end{array}$ & $\begin{array}{c}4.125 \\
6\end{array}$ & $\begin{array}{c}1.557 \\
9\end{array}$ & $\begin{array}{c}1.140 \\
2\end{array}$ \\
\hline A9 & $\begin{array}{c}4.101 \\
7 \\
\end{array}$ & $\begin{array}{c}3.692 \\
8 \\
\end{array}$ & $\begin{array}{c}3.750 \\
6 \\
\end{array}$ & $\begin{array}{c}2.448 \\
2 \\
\end{array}$ & $\begin{array}{c}1.647 \\
0 \\
\end{array}$ \\
\hline A 10 & $\begin{array}{c}2.610 \\
1\end{array}$ & $\begin{array}{c}3.692 \\
8\end{array}$ & $\begin{array}{c}2.625 \\
4\end{array}$ & $\begin{array}{c}2.003 \\
1\end{array}$ & $\begin{array}{c}1.520 \\
3\end{array}$ \\
\hline A 11 & $\begin{array}{c}3.355 \\
9\end{array}$ & $\begin{array}{c}4.062 \\
1\end{array}$ & $\begin{array}{c}4.500 \\
7\end{array}$ & $\begin{array}{c}2.893 \\
4 \\
\end{array}$ & $\begin{array}{c}1.520 \\
3\end{array}$ \\
\hline A12 & $\begin{array}{c}2.983 \\
0\end{array}$ & $\begin{array}{c}2.954 \\
3\end{array}$ & $\begin{array}{c}4.875 \\
7\end{array}$ & $\begin{array}{c}2.003 \\
1\end{array}$ & $\begin{array}{c}1.266 \\
9\end{array}$ \\
\hline A 13 & $\begin{array}{c}4.474 \\
6\end{array}$ & $\begin{array}{c}2.954 \\
3\end{array}$ & $\begin{array}{c}2.625 \\
4\end{array}$ & $\begin{array}{c}2.448 \\
2\end{array}$ & $\begin{array}{c}1.647 \\
0\end{array}$ \\
\hline A14 & $\begin{array}{c}4.101 \\
7\end{array}$ & $\begin{array}{c}3.692 \\
8\end{array}$ & $\begin{array}{c}2.625 \\
4\end{array}$ & $\begin{array}{c}2.225 \\
7\end{array}$ & $\begin{array}{c}1.520 \\
3\end{array}$ \\
\hline
\end{tabular}

Setelah hasil matriks keputusan normalisasi terbobot diperoleh, langkah selanjutnya adalah menentukan nilai solusi ideal positif dan solusi ideal negatif. Persamaan (3) digunakan untuk mencari nilai solusi ideal positif dan persamaan (4) digunakan untuk mencari nilai solusi ideal negatif. Nilai matriks solusi ideal positif dapat dilihat pada tabel 7 dan nilai matriks solusi ideal negatif dapat dilihat pada tabel 8 .

Tabel 7. Matriks solusi ideal positif

\begin{tabular}{c|c|c|c|c}
\hline \multicolumn{1}{c}{ C1 } & C2 & C3 & C4 & C5 \\
\hline 1.8644 & 2.2157 & 1.8753 & 1.3354 & 0.7601 \\
\hline \multicolumn{5}{c}{ Tabel 8. Matriks solusi ideal negatif } \\
\hline C1 & C2 & C3 & C4 & C5 \\
\hline 4.8475 & 4.8007 & 4.8757 & 2.8934 & 1.7737 \\
\hline
\end{tabular}

Langkah selanjutnya menentukan jarak antara alternatif $\mathrm{A}_{\mathrm{i}}$ dengan solusi ideal positif menggunakan persamaan (5) dan persamaan (6) untuk menentukan jarak antara alternatif $\mathrm{A}_{\mathrm{i}}$ dengan solusi ideal negatif. Hasil dari perhitungan jarak antara alternatif dari solusi ideal dan negatif dapat dilihat pada tabel 9 .

\begin{tabular}{c|c|c}
\hline \multicolumn{3}{c}{ Tabel 9. Tabel Separasi } \\
\hline \multicolumn{3}{c}{ TABEL MATRIKS } \\
PENDEKATAN IDEAL \\
\hline & NEGATIF & POSITIF \\
\hline A1 & 2.2953 & 3.7651 \\
\hline A2 & 2.4771 & 3.2020 \\
\hline A3 & 3.9849 & 1.6614 \\
\hline A4 & 3.4101 & 2.3706 \\
\hline A5 & 3.7026 & 1.7645 \\
\hline A6 & 3.6439 & 2.7866 \\
\hline A7 & 2.8931 & 3.1261 \\
\hline A8 & 2.7530 & 3.2844 \\
\hline A9 & 3.5678 & 1.8065 \\
\hline A10 & 2.0795 & 3.4862 \\
\hline A11 & 3.9410 & 1.7248 \\
\hline A12 & 3.3915 & 2.8168 \\
\hline A13 & 3.1537 & 2.9709 \\
\hline A14 & 3.0200 & 2.7125 \\
\hline
\end{tabular}

Setelah didapat nilai jarak alternatif dari solusi ideal positif dan negatif, maka langkah selanjutnya adalah menghitung kedekatan relatif terhadap solusi ideal positif dengan menggunakan persamaan (7). Nilai kedekatan relatif dapat dilihat pada tabel 10 .

Tabel 10. Tabel Kedekatan Relatif

\begin{tabular}{c|c}
\hline \multicolumn{2}{c}{ Kedekatan } \\
\hline A1 & 0.3787 \\
\hline A2 & 0.4361 \\
\hline A3 & 0.7057 \\
\hline A4 & 0.5899 \\
\hline A5 & 0.6772 \\
\hline A6 & 0.5666 \\
\hline A7 & 0.4806 \\
\hline A8 & 0.4559 \\
\hline A9 & 0.6638 \\
\hline A10 & 0.3736 \\
\hline A11 & 0.6955 \\
\hline A12 & 0.5462 \\
\hline A13 & 0.5149 \\
\hline A14 & 0.5268 \\
\hline
\end{tabular}

Langkah terakhir adalah mengurutkan alternatif terhadap kedekatan relatif terhadap solusi ideal positif, dilakukan perankingan untuk mengetahui nilai tertinggi dari seluruh alternatif. Hasil dari perankingan dapat dilihat pada tabel 11 . 


Tabel 11. Perangkingan
\begin{tabular}{c|c} 
& Rangking \\
\hline A1 & 45 \\
\hline A2 & 42 \\
\hline A3 & 3 \\
\hline A4 & 16 \\
\hline A5 & 7 \\
\hline A6 & 18 \\
\hline A7 & 34 \\
\hline A8 & 36 \\
\hline A9 & 9 \\
\hline A10 & 46 \\
\hline A11 & 4 \\
\hline A12 & 21 \\
\hline A13 & 28 \\
\hline A14 & 25 \\
\hline
\end{tabular}

\section{KESIMPULAN}

Berdasarkan penelitian yang telah dilakukan, dapat ditarik beberapa kesimpulan sebagai berikut :

1. Alternatif yang terpilih menjadi yang terbaik adalah Sekta Lonir Oscarini Wati Bhakti, S.Pd., M.Pd

2. Hasil dari perhitungan menggunakan metode tidak memiliki nilai yang sama sedangkan perhitungan yang tidak menggunakan metode terdapat beberapa nilai yang sama.

Dengan kesimpulan diatas maka metode TOPSIS dapat diterapkan pada seleksi proposal dan dikembangkan dalam bentuk aplikasi.

\section{REFERENSI}

[1] A. Rekrutmen et al., "PT ARTA BOGA

CEMERLANG SURABAYA," vol. 2, no. 1, 2014.

[2] N. G. Perdana and T. Widodo, "Sistem Pendukung Keputusan Pemberian Beasiswa Kepada Peserta Didik Baru Menggunakan Metode TOPSIS," vol. 2013, no. November, pp. 265-272, 2013.

[3] et al. S. Kusumadewi, S. Hartati, A. Harjoko, R. Wardoyo, Fuzzy Multi-Atribute Decision Making $(M A D M)$. Yogyakarta: Yogyakarta : Graha Ilmu, 2006. 